втручанням достовірно збільшує тривалість перебування в стаціонарі серед дорослих пацієнтів. Наразі немає опублікованих даних щодо рівня глікемічного контролю в дітей з ЦД I типу у Вінницькій області, що є надзвичайно важливим при оцінці ризику ускладнень та результатів лікування цієї популяції в хірургічному стаціонарі.

Мета - проаналізувати та оцінити поширеність і глікемічний контроль серед дітей з ЦД I типу у Вінницькій області у 2013, 2016 та 2017 рр.

Матеріали та методи. Проведено ретроспективну оцінку динаміки поширеності ЦД I типу серед дитячої популяції Вінницької області в період 2013-2017 рр. шляхом аналізу звітів Вінницького обласного клінічного високоспеціалізованого ендокринологічного центру та демографічних даних Головного управління статистики у Вінницькій області, карт стаціонарних хворих, що лікувалися в КНП «Вінницька обласна дитяча клінічна лікарня Вінницької обласної ради».

Кількість пацієнтів з ЦД І типу у 2013 р. становила 321, у 2016 р. - 358, у 2017 р. - 399 особи. Для оцінки глікемічного контролю використано показник НbАc1. Значення НbAc1 $\leq 7,5 \%$ прийнято за цільове, >7,5-9,0\% - за субоптимальне, >9,1\% - за незадовільне. Пацієнтів з відсутніми показниками HbAc1 вилучено з подальшого дослідження. Для оцінки достовірної різниці показників застосовано точний тест Фішера. Значення р<0,05 прийнято статистично значущим.

Результати. Протягом періоду дослідження відмічалося зростання поширеності ЦД І типу в дитячій популяції. Зокрема, у 2013 р. цей показник дорівнював 1,08\%, у 2016 р. - 1,23\%, а у 2017 р. - 1,37\% (p=0,1266; p=0,0015, порівняно з 2017 р. відповідно), що відповідає очікуваним світовим тенденціям. Первинна захворюваність на цД І типу у Вінницькій області становила: у 2013 р. - 0,017\%, у 2016 р. 0,015\%, у 2017 р. - 0,022\%, із піком маніфестації в 6 і 10-річному віці. Середні показники глікемічного контролю на основі НbА1c

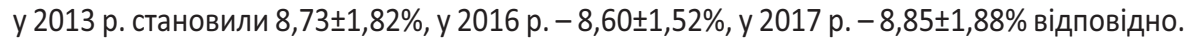

У 2013 р. глікемічний контроль оцінювався як оптимальний у 27,5\% (88/319) дітей, субоптимальний - у 37,5\% (120/319), незадовільний-у $35 \%$ (111/319).

У 2016 р. кількість пацієнтів з оптимальними показниками НbAc1 зменшилася до 25\% (83/336), субоптимальний рівень відмічався у $41 \%$ (139/336), незадовільний - у $34 \%$ (114/336) відповідно.

У 2017 р. цільовий рівень НbАс1 спостерігався лише у 21\% (68/329), субоптимальний - у 41\% (135/329), незадовільний - у 38\% (126/329) відповідно.

Зростала кількість пацієнтів із незадовільним глікемічним контролем та показниками HbA1c, що перевищувало 11\%: у 2017 р. (42/329) порівняно з відповідним показником 2016 р. (24/336), p=0,0191.

Клінічними проявами незадовільного глікемічного контролю в досліджуваній популяції були гострі ускладнення (кетоз, кетоацидоз), що супроводжувались абдомінальним синдромом, нудотою та блюванням і потребували лікування у відділенні інтенсивної допомоги. Гнійно-запальні захворювання органів черевної порожнини в дітей з ЦД I типу супроводжувалися комбінацією клініколабораторних даних декомпенсації ЦД I типу, гіперлейкоцитозом і дифузним болем у животі. Макроскопічні та патоморфологічні характеристики апендикса й очеревини відповідали деструктивним формам ГЗЗ за наявності короткого періоду від маніфестації симптомів. Перебіг післяопераційного періоду в дітей з ГЗЗ органів черевної порожнини на тлі ЦД I типу носив лабільний характер та потребував інсулінокорекції.

Висновки. Поширеність цукрового діабету I типу серед дітей Вінницької області зростає (2013 р. - 1,08\%, 2017р. - 1,37\%о, p=0,0015). Глікемічний контроль у цій популяції знаходиться в субоптимальних межах (>7,5-9,0\%) протягом періоду 2013-2017 рр. Станом на 2017 р. більше третини пацієнтів дитячого віку (38\%) мають незадовільний глікемічний контроль. Кількість пацієнтів із показником НbA1c >11\% достовірно зросла в 2017 р. порівняно з 2016 р. (p=0,0191).

Дослідження виконано відповідно до принципів Гельсінської декларації. Протокол дослідження ухвалено Локальним етичним комітетом усіх зазначених у роботі установ. На проведення досліджень отримано інформовану згоду пацієнтів.

Автори заявляють про відсутність конфлікту інтересів.

Ключові слова: діабет цукровий, глікемічний контроль, глікозильований гемоглобін, діти.

\title{
Dynamic assessment of prevalence and glycemic control in type I diabetes mellitus among the pediatric population
}

\author{
O. Yakimenko, O. Fischuk, S. Suchok
}

\section{National Pirogov Memorial Medical University, Vinnytsya, Ukraine}

Glycated hemoglobin ( $\mathrm{HbAc1}$ ) remains one of the most valuable methods of glycemic control among patients with diabetes mellitus (DM). Its target level in children and adolescents is $\leq 7 \%$ according to the recommendations of ISPAD (2018) and $\leq 7.5 \%$ - ADA (2020), but the presence of complications and labile course of type I diabetes mellitus (T1DM) in children and adolescents requires an individual approach to achieve optimal glycemic control. The level of glycated hemoglobin determines the risk of concomitant purulent-inflammatory diseases (PID) and the restoration of systemic homeostasis after the surgery. High HbAc1 levels during the last 90 days before the surgery significantly increase the length of hospital stay among adult patients. Currently, there are no published data on the level of glycemic control in children with T1DM in Vinnytsia region, which is extremely important in assessing the risk of complications and treatment outcomes of this population in a surgical department. 
Purpose - to analysis and assessment of the prevalence of T1DM and glycemic control among children with T1DM in Vinnytsia region in 2013, 2016 and 2017.

Materials and methods. We carried a retrospective study to assess the prevalence of T1DM among the pediatric population of Vinnytsia region through the period from 2013 to 2017 by analyzing the reports of the Vinnytsia Regional Clinical Endocrinology Center and demographic data of the Main Department of Statistics in Vinnytsia Region, case histories of patients treated at Vinnytsia Regional Children's Hospital. Number of patients with T1DM in 2013 was - 321, in 2016-358, in 2017-399 patients. The study was conducted in accordance with the principles of the Declaration of Helsinki. Informed consent was obtained from parents to conduct the research. HbAc1 was used to assess glycemic control. The value of $\mathrm{HbAc1} \leq 7.5 \%$ was considered as optimal, $>7.5-9.0 \%$ - suboptimal, $>9.1 \%$ - poor. Patients with no HbAc1 available were excluded from further study. Fisher's exact test was used to compare the groups. P-value $<0.05$ was considered statistically significant.

Results. During the study period, there was an increase in the prevalence of T1DM in the pediatric population. Particularly, in 2013 this indicator was equal to $-1.08 \%$, in $2016-1.23 \%$, and in $2017-1.37 \%$ ( $p=0.1266 ; p=0.0015$, compared to 2017 , respectively), which corresponds to the estimated global trends. The primary incidence of T1DM in Vinnytsia region was: $0.017 \%$ in $2013,0.015 \%$ in $2016,0.022 \%$ in 2017 , with the peak of the manifestation at the age of 6 and 10 . Average indicators of glycemic control based on $\mathrm{HbA1c}$ were at the level of $8.73 \pm 1.82 \%$ in 2013 , $8.60 \pm 1.52 \%$ in $2016,8.85 \pm 1.88 \%$ in 2017 , respectively.

In 2013 glycemic control was assessed as optimal in $27.5 \%$ (88/319) of children, suboptimal - 37.5\% (120/319), poor - 35\% (111/319).

In 2016 the number of patients with optimal HbAc1 decreased to 25\% (83/336), suboptimal level was found in 41\% (139/336), poor - in 34\% (114/336), respectively.

In 2017 the optimal level of HbAc1 was recorded in only 21\% (68/329), suboptimal - in 41\% (135/329), poor - in 38\% (126/329), respectively. There is an increase in the number of patients with poor glycemic control and HbA1c exceeding $11 \%$ in 2017 (42/329) compared to the corresponding indicator in 2016 (24/336), p=0.0191.

Clinical manifestations of poor glycemic control in the study population were acute complications (ketosis, ketoacidosis), which were accompanied by abdominal pain, nausea and vomiting and required treatment in the intensive care unit. Purulent-inflammatory diseases (PID) of the abdominal cavity in children with T1DM were accompanied by a combination of clinical and laboratory data of decompensation of T1DM, a significant increase in WBC and diffuse abdominal pain. Macroscopic and pathomorphological characteristics of the appendix and peritoneum corresponded to destructive forms of PID in the presence of a short period from the disease onset. The course of the postoperative period in children with PID of the abdominal cavity in the setting of T1DM was labile and required insulin correction.

Conclusions. The prevalence of T1DM among children in Vinnytsia region is growing (1.08\%o - in 2013, in 1.37\%o - in 2017; $p=0.0015)$. Glycemic control in this population is within suboptimal limits (>7.5-9.0\%) during the period from 2013 to 2017. As of 2017, more than a third of pediatric patients (38\%) have poor glycemic control. The number of patients with $\mathrm{HbA} 1 \mathrm{c}>11 \%$ significantly increased in 2017 compared to 2016 ( $p=0.0191)$.

The research was carried out in accordance with the principles of the Helsinki declaration. The study protocol was approved by the Local ethics committee of the participating institution. The informed consent of the patient was obtained for conducting the studies.

No conflict of interest was declared by the authors.

Key words: type I diabetes mellitus, glycemic control, glycated hemoglobin, children.

\title{
Динамическая оценка распространенности и гликемического контроля сахарного диабета I типа в детской популяции
}

\author{
А. Г. Якименко, О. О. Фищук, С. А. Сучок
}

Винницкий национальный медицинский университет имени Н. И. Пирогова, Украина

\begin{abstract}
Гликозилированный гемоглобин (HbAc1) остается одним из наиболее ценных методов гликемического контроля у пациентов с сахарным диабетом (СД). Его целевой уровень у детей и подростков составляет $\leq 7 \%$ (по рекомендациям ISPAD; 2018) и $\leq 7,5 \%$ (ADA; 2020), однако наличие осложнений и лабильного течения СД I типа у детей и подростков предполагает индивидуальный подход для достижения оптимального контроля. Уровень гликозилированного гемоглобина определяет риск развития сопутствующих гнойновоспалительных заболеваний (ГВЗ) и восстановление системного гомеостаза после хирургического вмешательства. Повышенный уровень $\mathrm{HbAc1}$ за последние 90 суток перед оперативным вмешательством достоверно увеличивает продолжительность пребывания в стационаре среди взрослых пациентов. В настоящее время отсутствуют опубликованные данные относительно уровня гликемического контроля у детей с СД I типа в Винницкой области, что чрезвычайно важно при оценке риска осложнений и результатов лечения данной популяции в хирургическом стационаре.

Цель - проанализировать и оценить распространенность и гликемический контроль среди детей с СД I типа в Винницкой области в 2013, 2016 и 2017 гг.

Материалы и методы. Проведена ретроспективная оценка динамики распространенности СД I типа среди детской популяции Винницкой области в период 2013-2017 гг. путем анализа отчетов Винницкого областного клинического высокоспециализированного эндокринологического центра и демографических данных Главного управления статистики в Винницкой области карт стационарных больных, лечившихся в КНП «Винницкая областная детская клиническая больница Винницкого областного совета». Количество
\end{abstract}


пациентов с СД І типа в 2013 г. составило 321, в 2016 г. - 358, в 2017 г. - 399 человек. Для оценки гликемического контроля использован показатель НbAc1. Значение НbAc1 $\leq 7,5 \%$ принято за целевое, > 7,5-9,0\% - субоптимальное, >9,1\% - неудовлетворительное. Пациенты с отсутствующими показателями $\mathrm{HbAc1}$ исключены из дальнейшего исследования. Для оценки достоверной разности характеристик применен чёткий тест Фишера. Значение р<0,05 принято статистически значимым.

Результаты. В течение периода исследования наблюдался рост распространенности СД I типа в детской популяции. В частности, в 2013 г. этот показатель был равен 1,08\%о, в 2016 г. - 1,23\%, а в 2017 г. - 1,37\%о (p=0,1266; p=0,0015, по сравнению с 2017 г. соответственно), что соответствует ожидаемым мировым тенденциям. Первичная заболеваемость СД I типа в Винницкой области составила: в 2013 г. - 0,017\%, в 2016 г. - 0,015\%, в 2017 г. - 0,022\%, с пиком манифестации в 6 и 10-летнем возрасте. Средние

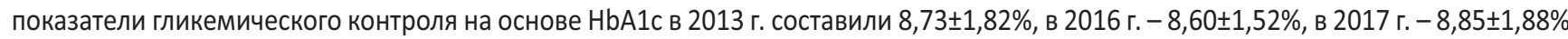
соответственно.

В 2013 г. гликемический контроль оценивался как оптимальный у 27,5\% (88/319) детей, субоптимальный - у 37,5\% (120/319), неудовлетворительный-у $35 \%$ (111/319).

В 2016 г. количество пациентов с оптимальными показателями HbAc1 уменьшилось до 25\% (83/336), субоптимальный уровень наблюдался у 41\% (139/336), неудовлетворительный - у 34\% (114/336) соответственно.

В 2017 г. целевой уровень НbAc1 отмечался только у 21\% (68/329), субоптимальный - у 41\% (135/329), неудовлетворительный - у 38\% (126/329) соответственно.

Отмечался рост количества пациентов с неудовлетворительным гликемическим контролем и показателями HbA1c, что превышало 11\%: в 2017 г. (42/329) по сравнению с соответствующим показателем 2016 г. (24/336), p=0,0191.

Клиническими проявлениями неудовлетворительного гликемического контроля в исследуемой популяции были острые осложнения (кетоз, кетоацидоз), которые сопровождались абдоминальным синдромом, тошнотой и рвотой и требовали лечения в отделении интенсивной помощи. Гнойно-воспалительные заболевания органов брюшной полости у детей с СД I типа сопровождались комбинацией клинико-лабораторных данных декомпенсации СД I типа, гиперлейкоцитозом и диффузной болью в животе. Макроскопические и патоморфологические характеристики аппендикса и брюшины соответствовали деструктивным формам ГВ3 при наличии короткого периода от манифестации симптомов. Течение послеоперационного периода у детей с ГВЗ органов брюшной полости на фоне СД I типа носило лабильный характер и требовало инсулинокоррекции.

Выводы. Распространенность СД I типа среди детей Винницкой области растет (2013 г. -1,08\%о, 2017 г. - 1,37\%о, p=0,0015). Гликемический контроль в этой популяции находится в субоптимальных пределах (>7,5- $\leq 9,0 \%)$ в течение периода 2013-2017 гг. По состоянию на 2017 г. более трети пациентов детского возраста (38\%) имеют неудовлетворительный гликемический контроль. Количество пациентов с показателем НbA1c>11\% достоверно увеличилось в 2017 г. по сравнению с 2016 г. (p=0,0191).

Исследование выполнено в соответствии с принципами Хельсинкской декларации. Протокол исследования одобрен Локальным этическим комитетом участвующего учреждения. На проведение исследований получено информированное согласие пациентов. Авторы заявляют об отсутствии конфликта интересов.

Ключевые слова: диабет сахарный, гликемический контроль, гликозилированный гемоглобин, дети.

References/Лiтература

1. American Diabetes Association. (2020). Children and Adolescents: Standards of Medical Care in Diabetes-2020. Diabetes Care. 43 (1): S163-s182. URL: https://doi.org/10.2337/dc20-S013.

2. DiMeglio LA, Acerini CL, Codner E, Craig ME, Hofer SE, Pillay K, Maahs DM. (2018). ISPAD Clinical Practice Consensus Guidelines 2018: Glycemic control targets and glucose monitoring for children, adolescents, and young adults with diabetes. Pediatr Diabetes. 19 (27): 105-114. URL: https://doi.org/10.1111/pedi.12737.

3. Hloba YeV, Zelinska NB. (2021). Hlikemichnyi kontrol u ditei i molodykh doroslykh z riznymy typamy tsukrovoho diabetu v Ukraini. Clinical Endocrinology and Endocrine Surgery. 73 (1): 7-14. [Глоба ЄB, Зелінська НБ. (2021). Глікемічний контроль у дітей і молодих дорослих з різними типами цукрового діабету в Україні. Clinical Endocrinology and Endocrine Surgery. 73 (1): 7-14].

4. Patterson CC, Karuranga S, Salpea P, Saeedi P, Dahlquist G, Soltesz G, Ogle GD. (2019). Worldwide estimates of incidence, prevalence and mortality of type 1 diabetes in children and adolescents: Results from the International Diabetes Federation Diabetes Atlas. 9th edition. Diabetes Research and Clinical Practice: 157. URL: https://doi.org/10.1016/j.diabres.2019.107842.

5. Underwood P, Askari R, Hurwitz S, Chamarthi B, Garg R. (2014). Preoperative A1C and clinical outcomes in patients with diabetes undergoing major noncardiac surgical procedures. Diabetes Care. 37 (3): 611-616. URL: https://doi.org/10.2337/dc13-1929. 


\section{Правила подачі та оформлення статей}

Авторська стаття направляється до редакції електронною поштою у форматі MS Word. Стаття супроводжується офіційним направленням від установи, в якій була виконана робота, з візою керівництва (наукового керівника), завіреним круглою печаткою установи, експертним висновком про можливість відкритої публікації, висновком етичного комітету установи або національної комісії з біоетики. На останній сторінці статті мають бути власноручні підписи всіх авторів та інформація про відсотковий внесок у роботу кожного з авторів.

Приймаються оригінали супровідних документів з примірником рукопису, підписаного автором(ами), надіслані поштою, або скановані копії вищезазначених документів і першої (титульної) сторінки статті з візою керівництва, печаткою установи і підписами всіх авторів у форматі Adobe Acrobat (*.pdf), надіслані на електронну адресу редакції.

Статті приймаються українською, російською або англійською мовами.

Структура матеріалу: вступ (стан проблеми за даними літератури не більше ніж 5-7-річної давності); мета, завдання, матеріали та методи; результати дослідження та їх обговорення (висвітлення статистично опрацьованих результатів дослідження); висновки; перспективи подальших досліджень у даному напрямку; список літератури (два варіанти); реферати українською, російською та англійською мовами.

Реферат $є$ незалежним від статті джерелом інформації, коротким і послідовним викладенням матеріалу публікації за основними розділами і має бути зрозумілим без самої публікації. Його обсяг не повинен перевищувати 200-250 слів. Обов’язково подаються ключові слова (від 3 до 8 слів) у порядку значущості, що сприятиме індексуванню статті в інформаційно-пошукових системах.

Реферат до оригінальної статті повинен мати структуру, що повторює структуру статті: мета дослідження; матеріали і методи; результати; висновки; ключові слова. Усі розділи у рефераті мають бути виділені в тексті жирним шрифтом.

Для інших статей (огляд, лекція, клінічний випадок тощо) реферат повинен включати короткий виклад основної концепції статті та ключові слова.

Оформлення статті. На першій сторінці зазначаються: індекс УДК ліворуч, ініціали та прізвища авторів, назва статті, назва установ, де працюють автори та виконувалось дослідження, місто, країна.

За умови проведення досліджень із залученням будь-яких матеріалів людського походження, в розділі «Матеріали і методи» автори повинні зазначати, що дослідження проводилися відповідно до стандартів біоетики, були схвалені етичним комітетом установи або національною комісією з біоетики. Те саме стосується і досліджень за участю лабораторних тварин.

Наприклад: «Дослідження виконані відповідно до принципів Гельсінської Декларації. Протокол дослідження ухвалений Локальним

етичним комітетом (ЛЕК) всіх зазначених у роботі установ. На проведення досліджень було отримано поінбормовану згоду

батьків дітей (або їхніх опікунів)».

«Під час проведення експериментів із лабораторними тваринами всі біоетичні норми та рекомендаиї були дотримані».

Кількість ілюстрацій (рисунки, схеми, діаграми, фото) має бути мінімальною. Діаграми, графіки, схеми будуються у програмах Word або Excel; фотографії повинні мати один із наступних форматів: PDF, TIFF, PSD, EPS, AI, CDR, QXD, INDD, JPG (150-600 dpi).

Таблиці та рисунки розташовують у тексті статті відразу після першого згадування. У підпису до рисунку наводять його назву, розшифровують усі умовні позначки (цифри, літери, криві тощо). Таблиці мають бути оформлені відповідно до вимог ДАК, бути компактними, пронумерованими, мати назву. Номери таблиць, їхні заголовки і цифрові дані, оброблені статистично, повинні точно відповідати наведеним у тексті статті.

Посилання на літературні джерела у тексті позначаються цифрами у квадратних дужках та відповідають нумерації у списку літератури. Статті зі списком літературних джерел у вигляді посилань на кожній сторінці або кінцевих посилань не приймаються.

Необхідно подавати два варіанти списку літератури.

Перший варіант подається відразу після тексту статті, джерела розташовуються за алфавітом (спочатку праці, опубліковані українською або російською мовами, далі - іншими мовами).

Другий варіант повністю відповідає першому, але джерела українською та російською мовами ПЕРЕКЛАДАЮТЬСЯ! на англійську мову. Цей варіант необхідний для сайту, підвищення індексу цитування та аналізу статті у міжнародних наукометричних базах даних.

Обидва варіанти оформлюються за стилем АРA (American Psychological Association style), який використовується у дисертаційних роботах.

Приклад оформлення для обох варіантів:

Автор АА, Автор ВВ, Автор СС. (2005). Назва статті. Назва журналу. 10(2); 3: 49-53.

Автор АА, Автор ВB, Автор СС. (2006). Назва книги. Місто: Видавництво: 256.

У тексті статті допускаються загальноприйняті скорочення, а також авторські скорочення, які обов'язково розшифровуються у тексті при першому згадуванні та залишається незмінними по всьому тексту.

У кінці статті автори мають заявити про наявність будь-яких конкуруючих фінансових інтересів щодо написання статті. Зазначення конфлікту інтересів або його відсутності у статті є обов'язковим.

Приклад: «Автори заявляють про відсутність конблікту інтересів» або «Матеріал підготовлений за підтримки компанії...»

Стаття закінчується відомостями про усіх авторів. Зазначаються прізвище, ім'я, по батькові (повністю), вчений ступінь, вчене звання, посада в установі/установах, робоча адреса з поштовим індексом, робочий телефон і адреса електронної пошти; ідентифікатор ORCID (https://orcid.org/register). Автор, відповідальний за зв'язок із редакцією, надає свій мобільний/контактний номер телефона.

Відповідальність за достовірність та оригінальність наданих матеріалів (фактів, цитат, прізвищ, імен, результатів досліджень тощо) несуть автори.

Редакція забезпечує рецензування статей, виконує спеціальне та літературне редагування, залишає за собою право скорочувати обсяг статей. Відмова авторам у публікації статті може здійснюватись без пояснення причин и не вважається негативним висновком щодо наукової та практичної значущості роботи.

Статті, оформлені без дотримання правил, не розглядаються і не повертаються авторам. 


\section{2}

\section{АЬВІВСЬКИЙ МЕАИЧНИЙ ФОРУМ}

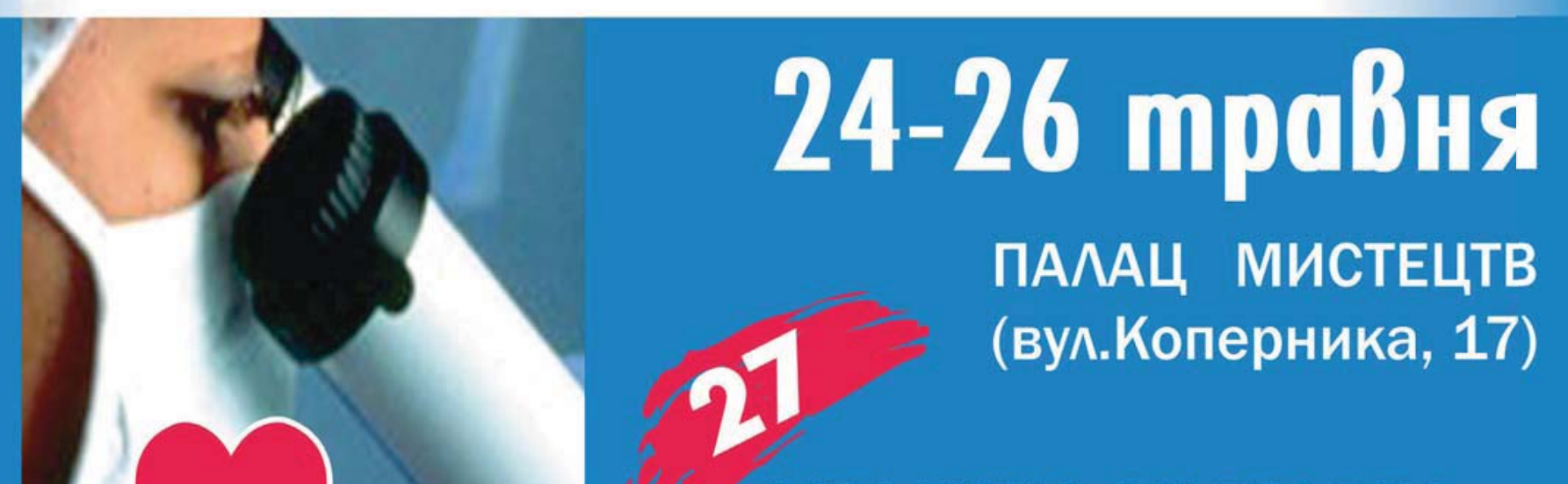

\section{МЕАИЧНА ВИСТАВКА}

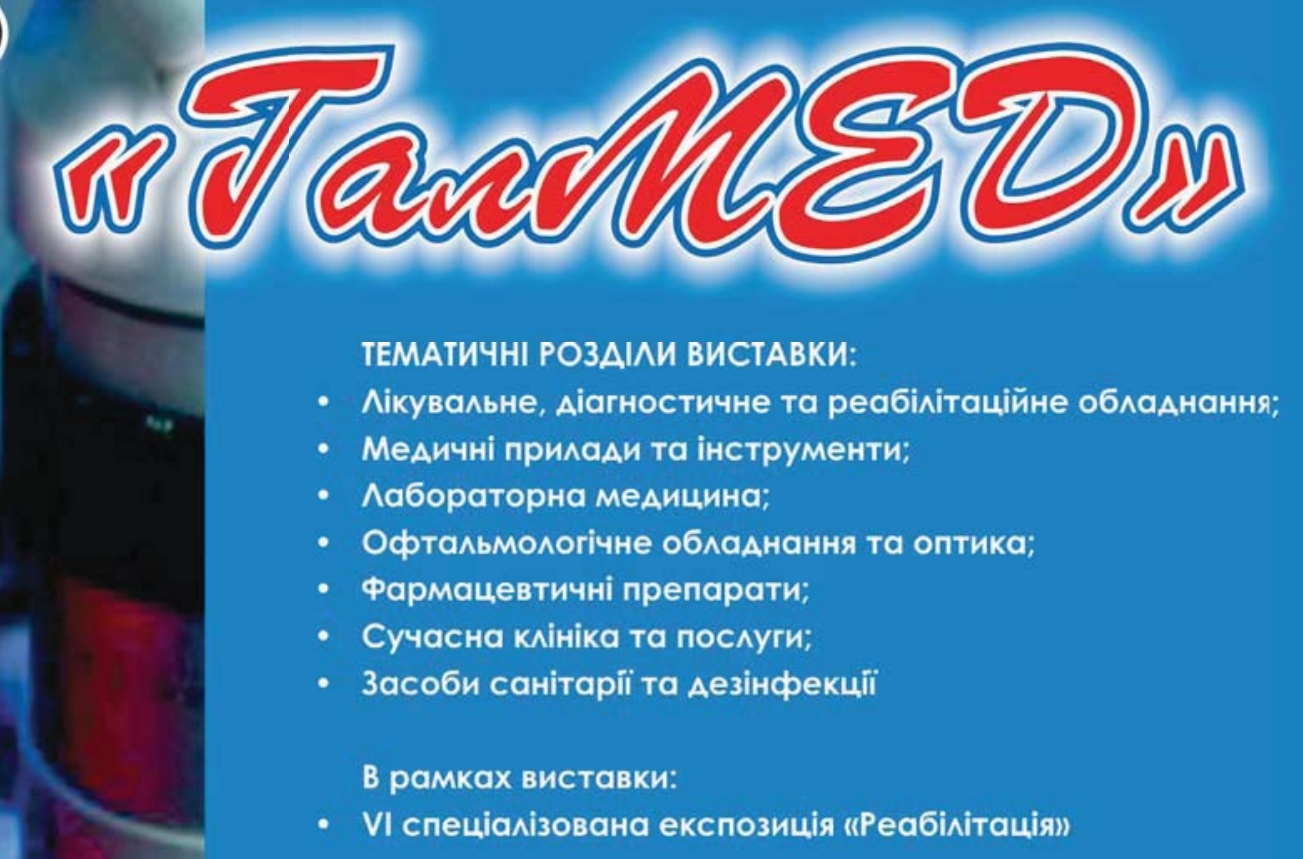

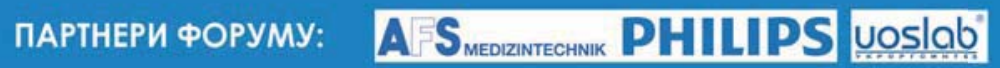

ПАРТНЕР ВИСТАВКИ:

ЗА ПІАТРИМКИ: $\quad$ Міністерства охорони зАоров'я України Аепартаменту охорони зАоров'я $А О А А$ Управління охорони зАоров'я ММР

ОРГАНІЗАТОР ФОРУМУ: 


\section{$\checkmark$ МІЖНАРОДНИЙ КОНГРЕС \\ 12-13 листопада 2022 on-line \\ Antibiotic resistance STOP!}

Стійкість до антибіотиків зростає до загрозливо високих рівнів у всьому світі. Нові механізми.стійкості з'являються і поширюються всюди, створюючи перешкоди для лікування розповсюджених інфекційних захворювань

- World Health Organization

\section{ANTIBIOTIC RESISTANCE}

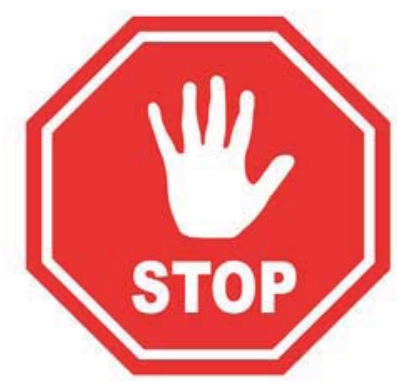

Розвиток нових антибіотиків має надзвичайне значення, оскільки еволюція мікробів продовжуватиметься безперервно, а резистентність долікарських засобів зростає.

Проблема антибіотикорезистентності стала глобальним викликом сьогодення. Головною його причиною вважають нераціональне застосування антибактеріальної терапії.

Тож під час Всесвітнього тижня поінформованості про антибіотики, в Українї традиційно буде проведено

IV міжнародний конгрес "Antibiotic resistance STOP!",

який об'єднає провідних спеціалістів медичної галузі для розробки стратегії контролю розвитку антибіотикорезистентності 